\title{
Electrical appliances control system by using iOS
}

\begin{abstract}
Today, Internet of Things technology is preferred compared to manual systems. With the rapid increases in the number of users of Internet over the past decade, this situation has made Internet a part and way of life. Internet of Things, IoT is the latest and emerging internet technology. Internet of Things is known as a growing network of everyday activities from industrial machine to consumer's goods that can share information and complete tasks while everyone is busy with other activities. Electrical appliances control by using IoT technology is a system that uses computers or mobile devices to control basic home functions and automatic features. It is meant to save the electric power and human energy to control electrical appliances operations. Electrical appliances control system by using IoT systems differs from other systems by allowing users to operate the systems from anywhere around the world through internet connection. In this paper, the project uses Blynk application that employs the integration of cloud networking and wireless communication by providing the user with remote control of various electrical appliances such as lights, fans, and air conditioner in the house.
\end{abstract}

Keyword: IoT; Electrical systems; iOS 